\title{
ARISTOTLE ON UNITY AND BEING
}

In this paper I will discuss what Aristotle has to say on the relation between $\tau \dot{0}$ है $\mathrm{v}$ and $\tau o ̀$ öv. Stated briefly the relation is that $\tau$ ò $\check{\varepsilon} v$ and $\tau$ ò öv are (a) transcendental predicates: each applies in all the categories; ${ }^{1}$ (b) convertible predicates: each implies the other and adds nothing to the other. ${ }^{2}$ For Met. $1003 \mathrm{~b} 23-4$ claims that being and unity are one and the same thing in that they are implied in each other,

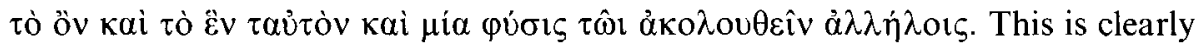
meant to apply in every category, since the convertibility claim is functioning as a premiss in an argument whose conclusion is that there are exactly as many types of being as of unity. At Met. 1061a17-18 there is an equally explicit statement of

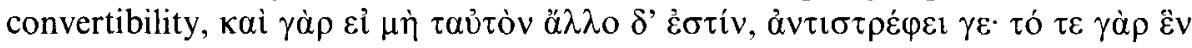

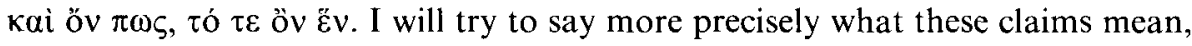
and come to some view on their philosophical plausibility.

There are a number of reasons for discussing these topics. First, it is a prolegomenon to a comprehensive discussion of all those predicates which came to be thought of as convertible and transcendental. ${ }^{3}$ Second, compared to the amount of attention given to Aristotle's treatment of $\tau$ ò ôv, comparatively little is said about his views on $\tau$ ò हैv. Third, the philosophical problems grouped round the notion of unity are of interest and are little considered nowadays. Fourth, it has long seemed to me difficult to get a clear understanding of what Aristotle has to say about $\tau \dot{\mathrm{o}} \ddot{\varepsilon} v$, especially in regard to its application in non-substance categories. How does $\tilde{\varepsilon} v$ apply in each of the categories? What, for example, is its application in the category of quality, and what does it mean to say that $\ddot{\varepsilon} v$ adds nothing to oov in that category? Fifth, there are a number of arguments throughout the history of philosophy based on the convertibility of unity and being, often to atomist conclusions. ${ }^{4}$ These arguments, which are of considerable interest in themselves, should be clarified by a discussion of Aristotle's account of the convertibility of unity and being.

There are distinctions to be drawn within the notion of $\tau \dot{o} \tilde{\varepsilon} v$, which Aristotle tends to treat in an undifferentiated way. In itself this is hardly a radical or original point. In the course of explicating Aristotle's ideas in his Commentary on the Metaphysics, Aquinas goes some way towards drawing the relevant distinctions. ${ }^{5}$ More recent commentators have made similar points. ${ }^{6}$ For example, the 
extent to which Aristotle has a concept of identity, which seems to be one of the concepts he treats under the heading tò $\tilde{\varepsilon} v$, has been much discussed. ${ }^{7}$ The question arises then as to how far the account $I$ offer of the convertibility of $\tau$ ò ob $v$ and $\tau$ ò हैv is Aristotle's own account. For the distinctions I will draw are not drawn by Aristotle, ${ }^{8}$ and some of the materials I use in my account come not from Aristotle but from Aquinas. My intention is to set out clearly what Aristotle is

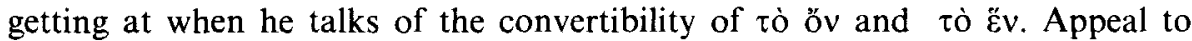
Aquinas' discussion helps us to give a philosophically plausible account of the claim that $\tau$ ò ö $v$ and $\tau$ ò $\tilde{\varepsilon} v$ are convertible. This procedure, of expounding a philosopher's views by means of concepts, distinctions and arguments not explicitly to be found in that philosopher, raises questions of considerable interest concerning what the exegesis of a philosopher's views is. How, for example, can the exegesis of a philosopher's views be 'accurate' when it relies upon concepts and distinctions not originally to be found in that philosopher? This is, however, not the place to embark upon a discussion of the philosophical issues connected with the enterprise of the history of philosophy. ${ }^{9}$

Before proceeding it is important to be clear as to the level of generality at which I intend the distinctions I draw to be made. At Met. $\Delta 7$ Aristotle draws distinctions within the use of $\tau$ ò óv at what could plausibly be called different levels. For example, there is the use in an accidental sense, the use per se which is divided among the categories, and the use as meaning that a statement is true. Within one of these uses - the use as divided by the categories - there is a second level of distinction, that between the use of obv in each of the various categories. Certain concepts which explicate differences at this latter level - for example, the notion of focal meaning - would not be appropriate to explicate such a distinction as that between zò ob as applied per se and as meaning that a statement is true. In the course of this paper I shall argue, among other things, that we should take $\tilde{\varepsilon} v$ as it occurs in the claim that oै $v$ and $\tilde{\varepsilon} v$ are convertible as a unity predicate rather than as an identity predicate. This distinction is a different level than the distinctions within the use of $\varepsilon^{v}$ between its uses in the different categories. It is the notion of focal meaning which explicates the distinctions within the use of $\ddot{\varepsilon} v$ as a unity predicate in the different categories. The distinction between $\tilde{\varepsilon} v$ as a unity predicate, as an identity predicate and as the principle of number are not explained in terms of the notion of focal meaning.

When we consider examples of the widely various and often apparently conflicting things Aristotle says about हैv we shall see the need to draw basic distinctions within the notion of $\ddot{\varepsilon} v$. I will argue that it can be seen in the abstract that $\tilde{\varepsilon} v$ can be taken in three significantly different ways, as a unity predicate, as an identity predicate and as the principle of number. These distinctions can be seen also in Aquinas. If $\tilde{\varepsilon} v$ and ö $v$ are convertible, है $v$ should be taken in one of these basic ways, as a unity predicate, and not, as others have often supposed, as 
the principle of number. Following from these points we shall see in outline how the convertibility thesis can be fruitfully understood in the case of both substance and non-substance categories. Further questions concerning the various applications of $\ddot{\varepsilon} v$ taken as a unity predicate fall, for the most part, outside the purview of this paper.

\section{I}

(1) The distinction between a unity predicate and an identity predicate in the abstract

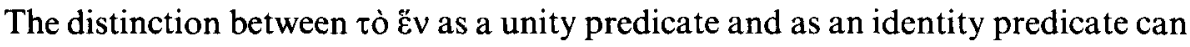
be illustrated in the abstract in various ways.

First as a distinction between one and two place usages of 'one $(F)$ '. Thus, the following are distinct:

(1) Cicero is one man.

(2) Cicero and Tully are one man.

(1) concerns a notion of unity, (2) of identity.

Second, the distinction is manifest if we consider different terms to which 'one' can be opposed..$^{10}$ There is a clear distinction between

(3) Cicero is one man (as opposed to a separated collection of limbs and organs).

(4) Cicero and Tully are one man (as opposed to two different men).

In (3) 'one' functions as a unity predicate, in (4) as an identity predicate.

Third, the following questions and answers are plainly distinct. ${ }^{11}$

(5) In virtue of what is Cicero one man? In virtue of his having a single function and well-being.

(6) In virtue of what are Cicero and Tully one man? In virtue of their being spatio-temporally coincident and continuous under a single sortal concept.

In (5) 'one' is a unity predicate, in (6) an identity predicate.

Fourth, the uses are distinct in the following semi-formal sentences.

(7) $x$ which is $F$ and $y$ which is $F$ are one $G$.

(8) $x$ which is $F$ and $y$ which is $F$ are one $F$.

In (8) 'one' is naturally replaceable by 'same', but this is not so with (7). Consider 'Alan who is a man and Bill who is a man are one tennis partnership'. This cannot be read as '.... are the same tennis partnership'. For if $A$ and $B$ are the same $F$ then $A$ is an F and B is an F. But neither Alan nor Bill is a tennis partnership. Hence in (7) 'one' is a unity predicate, and would be replaceable by 'a single', to give 'Alan who is a man and Bill who is a man are a single tennis partnership'.'2 
(2) The distinction between $\check{\mathrm{\varepsilon}} \mathrm{v}$ as a unity predicate and an identity predicate in Aristotle

Aristotle occasionally states what the application of transcendental predicates in

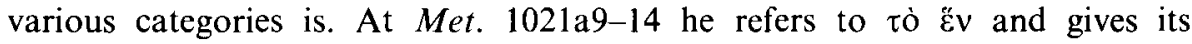
applications as the equal, the like and the same. ${ }^{13}$ Those things are the same whose substance is one, like whose quality is one and equal whose quantity is one. This suggests that the transcendental $\tau$ ò $\tilde{\varepsilon}^{\prime} \mathrm{v}$ is an identity predicate. The application in the category of substance would be 'the same', in quality 'alike' and in quantity 'equal'. This impression is reinforced by Met. $\Gamma 2$ where there is an extended discussion of the convertibility of $\tau$ ò öv and $\tau$ ò $\tilde{\varepsilon} v{ }^{14}$ The species of $\tau$ ò $\tilde{\varepsilon} v$ are given as the same, alike and such as these. ${ }^{15}$ The contraries of these concepts, derived from plurality and unity, are given as the other, the dissimilar and the unequal. ${ }^{16}$ In the discussion of $\tau \alpha{ }^{3} \tau \dot{\alpha}$ in Met. $\Delta 9$ sameness is explicated in terms of

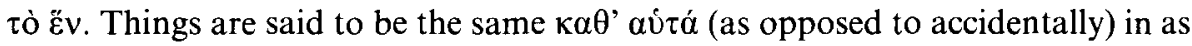
many ways as they are said to be one ${ }^{17}$ and sameness is said to be a kind of oneness. ${ }^{18}$ Further, in $\mathrm{Met} . \Gamma 2$ Aristotle refers to a list of contraries, and says that all the contraries are referred to being, non-being, $\tau$ ò $\ddot{\varepsilon} v$ and plurality. ${ }^{19}$ The opposition of $\tau$ ò $\tilde{\varepsilon} v$ and $\tau$ ò $\pi \lambda \hat{\eta} \theta 0 \varsigma$ suggests that $\tau \dot{o} \ddot{\varepsilon} v$ is taken as an identity predicate: what is not one is many because this $\mathrm{F}$ and that $\mathrm{F}$ are different $\mathrm{Fs}$, and hence not one $\mathrm{F}$ but many Fs. $\tau$ ò $\tilde{E} \mathrm{~V}$ appears again as an identity predicate at Met.

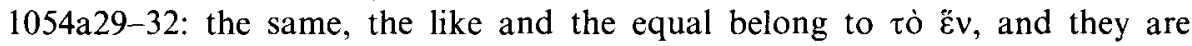
opposed to the other, the unlike and the unequal as types of $\tau \dot{0} \pi \lambda \hat{\eta} \theta$ os.

In view of such passages why should we suppose there is any notion of $\tau$ ò $\check{v} v$ to be distinguished from its use as an identity predicate? Consider first Met. Z16 in which Aristotle is concerned to criticise the view, canvassed at Met. 1028b9-13, that the parts of animals and plants, and such natural stuffs as fire and water, are substances. His conclusion at Met. 1041a3-5 is that no substance is composed from substances. Such things as the separated parts of animals, and earth and fire, are only potentialities. None of them is one, ${ }^{20}$ but they are like a heap before fusion into a single thing. The notion of $\tau$ ò $\tilde{\varepsilon} v$ here is not an identity predicate, but what we might call a unity predicate. The separated parts of animals, like the nuggets in an unfused heap of gold, lack cohesion and a unified structure. The upshot of their becoming one is not, for example, that nuggets of gold become the same nugget, for the nuggets either cease to exist when fused or maintain a separate identity. Nor is it that the nuggets become the same gold block, since fusion does not turn any particular nugget into a gold block. Further, when Aristotle says that even when they are naturally $\tilde{\varepsilon} v$ the parts of animals exist only potentially, ${ }^{21} \varepsilon^{\mathrm{E}} \mathrm{v}$ is not being used as an identity predicate. When the parts are naturally one they are neither the same part nor the same body, but are unified into a single whole. Further, the term offered in explication of है at Met. $1040 \mathrm{~b} 14-15$ is $\sigma v v \varepsilon \chi \varepsilon \dot{\varepsilon}$, which suggests a unity predicate rather than an identity 


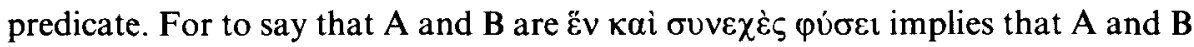
are different entities, of which the limits are one and the same and contained in each other. ${ }^{22}$

Politics 2.2 also manifests the use of $\tilde{\varepsilon} v$ as a unity predicate. For example, at 1261a20-1 Aristotle says that the individual is more one than the family, and the family more one than the state. This remark would not make sense if we were to think of $\varepsilon^{\prime} v$ as an identity predicate. The point clearly enough is that the individual is more of a structured whole than the family, and the family more of a structured whole than the state. $\varepsilon^{2} \mathrm{v}$ is thus taken as a unity predicate.

Consider now the text most obviously relevant to what Aristotle says about $\tau$ ò $\ddot{\varepsilon} v$, namely $M e t$. I1-3, where the distinction between $\tilde{\varepsilon} v$ as an identity predicate

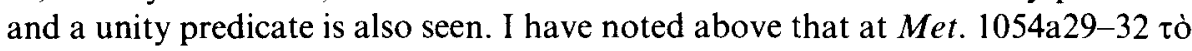
$\check{\varepsilon} \mathrm{v}$ appears as an identity predicate. But Met. Il starts with a summary of the various senses of $\tau$ ò $\tilde{\varepsilon} \mathrm{V}^{23}$ which are given as the naturally continuous, the whole, the individual and the universal. These are not identity predicates but unity predicates. For example, Aristotle speaks of what is naturally continuous, as opposed to being a collection of parts glued, nailed or tied together. Use of these unity predicates helps us to see how the notion of focal meaning ${ }^{24}$ is relevant in explaining the various applications of $\ddot{\varepsilon} v$. For just as the focus for uses of $\tau$ ò oै $v$ is the application in the category of substance ${ }^{25}$ so too the focus for uses of $\tau$ ò $\tilde{\varepsilon} v$ should be the application in the category of substance, given the convertibility of

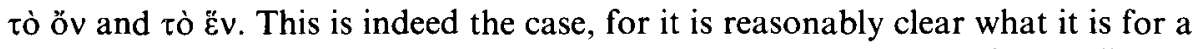
substance to be a continuous unity of parts, and so the unity of a quality or quantity seems derivative from that ${ }^{26}$ It seems plausible to hold, for example, that a particular occurrence of a colour is continuous just if it is the colour of a continuous object.

The distinction between $\tilde{E} v$ as a unity predicate and an identity predicate can be seen also at Met. 1054b18-23. Aristotle is considering the relation of 'same' and 'different'. They are not contradictories, since it is not the case for every A, B that $\mathbf{A}$ is either the same as or different from B. For example, it is neither the case that Holmes is the same (man) as Watson nor that Holmes is (a) different (man) from Watson, since neither Holmes nor Watson is an existent man - which according to Met. $\Gamma 2$ is equivalent to saying that neither Holmes nor Watson is a man nor one man. ${ }^{27}$ However, if we limit ourselves to things that are, then for any A, B either $\mathrm{A}$ is the same as, or is different from, B. Now tò oैv and tò ह̌v are convertible, and in this passage in $\mathrm{Met}$. $\mathrm{I} 3$ being-the-same is a kind of being-one. ${ }^{28}$

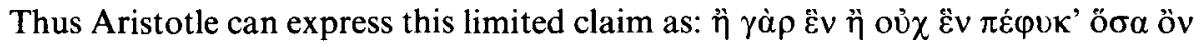
кai है ${ }^{29}$ But these occurrences of ${ }^{29} v$ should be understood differently. In the claim that 'things which are $\check{\varepsilon} v$ and oै $v$ are either $\varepsilon^{\prime} v$ or oủ $\chi \varepsilon^{\prime} v$ ' the second and third occurrences of " $\mathrm{v} v$ could be translated by 'same' and are identity predicates. But 1054b21-2 would read oddly if the first occurrence of $\tilde{\varepsilon} \mathrm{v}$ were treated in the same 
way: 'for if something is naturally existent and the same then it is either the same or not the same'. There is not a straightforward contradiction in this reading, since a particular thing can be both the same (as itself) and not the same (as something else) ${ }^{30}$ Rather, the first occurrence of है $v$ seems pointless if taken as an identity predicate. Since $\tau$ ò $\tilde{v} v$ has also been used as a unity predicate in close proximity to this passage ${ }^{31}$ it seems preferable to read $1054 \mathrm{~b} 21-2$ along the lines: 'if $A$ and $B$ are each existent and have their requisite unity, then either $A$ is the same as B or A is different from B'. Thus $\tilde{\varepsilon} v$ is functioning both as a unity predicate and as an identity predicate.

Met. $\mathrm{H} 6$ also reveals $\ddot{\varepsilon} v$ as a unity predicate. Aristotle gives a description of those cases in which there is a cause or explanation of unity. ${ }^{32}$ Of things which have parts, and where the whole is something more than a mere heap of its parts, the explanation of the unity of that whole could be, for example, contact or viscosity. There is here a clear case of $\ddot{\varepsilon} v$ treated as a unity predicate rather than an identity predicate.

Treating $\tau$ ò $\tilde{\varepsilon} v$ as a unity predicate promises to be more fruitful for understanding the convertibility of $\tau$ ò oै $v$ and $\tau$ ò Ěv. At Met. $\Gamma 2$ Aristotle expresses the convertibility of $\tau$ ò öv and $\tau$ ò $\varepsilon^{\nu} v$ by saying that they are not separated in comingto-be or passing-away. ${ }^{33}$ For example, for something to cease to be an existent man is for it to cease to be $\varepsilon \tilde{l} \zeta$ man. This could be read in terms of $\tilde{\varepsilon} v$ as an identity predicate: 'for A to cease to be an existent man is for A to cease to be the same man (as something)' ${ }^{34}$ But that is less explanatory than an alternative reading in terms of $\tilde{E}^{\mathrm{V}} \mathrm{v}$ as a unity predicate: 'for something to cease to be an existent man is for it to lose the unity (of parts) that renders it a man'. For that latter clarifies what ceasing-to-be-a-man is, and how it comes about - namely by the separation and dividing up of the component parts which make up a man. Further, at Met. $\mathrm{H} 2$ Aristotle considers what the substance of perceptible things is, in the sense of actuality. ${ }^{35}$ Examples follow which are relevant to the convertibility of tò ôv and $\tau o ̀ ~ \tilde{\varepsilon} v$, and where $\tau o ̀ ~ \tilde{\varepsilon} v$ is most enlighteningly taken as a unity predicate. For example, honey-water is characterized by its composition as a mixture (a certain unity of honey and water), a bundle by its being tied together (a type of unity), a casket by its being nailed together. ${ }^{36}$ For a casket to be actual is for it to be nailed together in a certain way, which is for it to have the type of unity appropriate to a casket. Here the convertibility of $\tau$ ò öv and $\tau$ ò $\tilde{E} v$ is manifest as the convertibility of actuality and unity. But again, if we were to read $\tilde{\varepsilon} v$ as an identity predicate we would have it, as an instance of the convertibility thesis, that for a casket to be actual is for it to be the same casket (as something). While this may be a true claim, it is less explanatory of what it is to bring a casket into actuality than appeal to the use of $\tilde{\varepsilon} v$ as a unity predicate would be.

We see therefore the need to draw a distinction in Aristotle between čv a $^{2}$ unity predicate and $\check{\varepsilon} v$ as an identity predicate. 
(3) The distinction between है $\mathrm{v}$ as a unity predicate, as the principle of number and as an identity predicate in Aquinas

We should expect some light to be cast on the convertibility of unity and being by what Aquinas has to say on the matter. At $S T$ 1a Q.11 Art. 1 Aquinas offers an argument - to which I shall return later - in support of the convertibility thesis, and attention to the concepts used in this argument reveals something of the philosophical issues involved in the claim that oov and $\tilde{\varepsilon} v$ are convertible. For, as Crispin Wright puts it, 'To understand any philosophical view involves knowing what best can be said on its behalf.' ${ }^{37}$ Further, Aquinas is explicit about the need to draw distinctions within the notion of $\tilde{\varepsilon} v$ in order to understand the convertibility of öv and $\ddot{E} v$. He regularly points out the need to distinguish between two notions of $\check{\varepsilon} v$, only one of which is convertible with being. ${ }^{38}$ According to Aquinas, philosophers such as the Pythagoreans, Plato, the Platonists and Avicenna fell into error through failing to draw this distinction. ${ }^{39}$ Aquinas distinguishes between the unity which is convertible with being (unum quod convertitur cum ente) and the unity which is the principle of number (unum quod est principium numeri). This second is distinct from the use of $\tilde{\varepsilon} v$ as an identity predicate. Aquinas also uses 'one' as a unity predicate, and it is that use which features in the argument of $S T$ 1a Q.11 Art.1. It appears sometimes, however, that Aquinas intends the unity convertible with being to be taken as an identity predicate. We shall see why this should be so, and why, nevertheless, it is concentration on $\tilde{\varepsilon} v$ as a unity predicate which is most fruitful for understanding the convertibility thesis.

I need not hold that Aquinas' discussion, even in his Commentary on Aristotle's Metaphysics, is intended as accurate exegesis of Aristotle's account. ${ }^{40}$ What I need to claim, and what I do indeed claim, is that attention to Aquinas' explicit concern with the convertibility thesis reinforces what was seen in the discussion of Aristotle above, namely the need to distinguish various notions covered by $\tilde{\varepsilon} v$ in order to understand convertibility.

At Comm. in Met. pr.552, glossing Aristotle's claim at Met. 1003b28-9 that

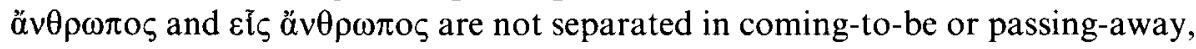
Aquinas comments that when a man is generated one man is generated, and when a man is corrupted one man is corrupted. We should take 'one' here as a unity predicate. If we read 'one' as opposed to 'two', 'three' etc. - that is, as a numerical term - then we come into conflict with Aquinas' distinction between the unity convertible with being and the unity which is the principle of number. On the other hand, taking 'one' as an identity predicate will not make good sense of Aquinas' claim.

At Comm. in Met. prs.1920-36, commenting on Met. 1052a15-1052b19, there is clear use of 'one' as a unity predicate. Aquinas speaks at pr. 1925 of what is one as a whole, having some form, as for example an animal is one, and adds that this 
sense of 'one' adds to the oneness of continuity the kind of unity which comes from the form by which a thing is a whole and has a species. Again, at Comm. in Met. pr.1926 he says that "whatever is joined by nature is one to the greatest degree, because it is clearly the cause of its own continuity; for it is such a thing by its very nature'. Summarizing the discussion of 1052a 15-1052b19 Aquinas writes at Comm. in Met. pr.1936 'Hence the essence of oneness consists in being undivided, i.e. in being an individual thing; and this is proper to a thing which is inseparable as to place or to form or in whatever other way it is inseparable.' Explication of these passages in terms of 'one' as an identity predicate or a numerical term is less plausible than in terms of 'one' as a unity predicate. For the unity which comes from the form by which a thing is a whole is precisely a structured unity of components.

At Comm. in Met. pr.1977, commenting on Aristotle's discussion of the convertibility of $\ddot{E} v$ and öv at Met. 1054a 13-18, Aquinas writes that 'everything is said to be one inasmuch as it is a being. Hence when a thing is dissolved it is reduced to non-being'. Being one is contrasted here with being dissolved, or dissociated, into component parts, and so the use of 'one' is as a unity predicate, a structured complex of parts.

Finally, at Comm. in Met. pr.1985 Aquinas' remark that the continuous is one because it is not divided, although it is divisible, clearly manifests the use of 'one' as a unity predicate.

However, besides taking 'one' as a unity predicate we also see Aquinas treating the $\check{\varepsilon} v$ convertible with being as an identity predicate. At Comm. in Met. pr.561 Aquinas outlines Aristotle's claim at Met. $\Gamma 2,1003 \mathrm{~b} 33$ that there are as many types of $\tilde{\varepsilon} v$ as there are types of öv, since öv and $\tilde{\varepsilon} v$ are convertible. Clearly it is the $\tilde{\varepsilon} v$ that is convertible with being which is under discussion here. But Aquinas describes these types of $\tilde{\varepsilon} v$ as sameness, equality and likeness, which are types of identity predicate. Hence $\check{\varepsilon} v$ as convertible with being is assimilated by Aquinas to $\tilde{\varepsilon} v$ as an identity predicate, rather than, as we might expect from the Aristotelian evidence discussed above, to $\check{\varepsilon} v$ as a unity predicate.

Further, at Comm. in Met. pr.1997 Aquinas points out that the notion of division connected with the Év convertible with beingll is not a division as regards quantity, but is the sort of division involved in saying that one thing is not another thing. Hence something that is $\tilde{\varepsilon} v$ in the sense of $\tilde{\varepsilon} v$ convertible with being is precisely not thus divided, since as being $\tilde{\varepsilon} v$ it is undivided. Thus the $\tilde{\varepsilon} v$ convertible with being appears as an identity predicate.

$\tilde{\varepsilon} v$ as the principle of number is distinct from $\ddot{\varepsilon} v$ as an identity predicate in Aquinas. At Comm. in Met. pr.501 the $\tilde{\varepsilon} v$ which is not that convertible with being is characterized in terms of a measure, and at pr.2090 it is stated that a measure is primarily connected with the category of quantity. ${ }^{42}$ This presumably connects with that strand in Aristotle's thought whereby to be $\tau$ ò $\tilde{\varepsilon} v$ is explicable primarily in terms of quantity, and is extended from the category of quantity to the other 
categories. ${ }^{43}$ But this would be implausible if the $\tilde{\varepsilon} v$ not convertible with being (the $\tilde{\varepsilon} v$ which is the principle of number) were taken as an identity predicate. For there is little plausibility in supposing that $\tilde{\varepsilon} v$ as an identity predicate applies primarily in the category of quantity, since we regularly have identity relations in other categories. For example, Cicero is Tully, Alan's height is the same as Bill's height, Alan's position is the same as Bill's position. Therefore the $\tilde{\varepsilon} v$ that is the principle of number is to be distinguished from $\tilde{\varepsilon} v$ as an identity predicate.

Thus we see in Aquinas the use of 'one' as a unity predicate, as an identity predicate and as the principle of number. We will see presently that it is understandable why Aquinas should in some passages treat the $\tilde{\varepsilon} v$ convertible with being as an identity predicate, for there are good grounds for taking identity also as a transcendental predicate convertible with being. Nevertheless, we do see 'one' used as a unity predicate in Aquinas, and that is how it features in the argument of $S T$ 1a Q.11 Art.1, to show that unity and being are convertible.

(4) The distinction between $\check{\varepsilon v}$ as an identity predicate and as the principle of number, in the abstract

It might be thought that the arguments above for distinguishing $\check{\varepsilon} v$ as an identity predicate and as the principle of number in Aquinas are sure to be weak, since there may appear to be no such distinction to be drawn in the abstract. For counting and identity go together: if $\mathrm{A}$ is an $\mathrm{F}$ and $\mathrm{B}$ is an $\mathrm{F}$ then $\mathrm{A}$ and $\mathrm{B}$ are two Fs just if $\mathrm{A}$ is not the same $\mathrm{F}$ as $\mathrm{B}$.

There is however a distinction to be drawn in the abstract between 'one' as an identity predicate and as the principle of number. Consider the following example. ${ }^{44}$ The Papal Crown in 1987 is the same crown as was the Papal Crown in 1900. A way of putting this would be: the Papal Crown in 1987 and the Papal Crown in 1900 are one crown. 'One' is there used as an identity predicate: they are the same crown as opposed to different crowns. But the Papal Crown in 1987 is countable as more than one crown numerically, for if the Papal Crown is composed of three crowns and is not itself the same crown as any of these three, then strictly it is countable as four crowns. 'One' in that connection would be considered as a numerical term, plausibly identifiable with what Aquinas terms one as the principle of number. The distinction is graphically illustrated by the odd sounding remark 'the Papal Crown and the Papal Crown are one crown, but the Papal Crown is four crowns'.

\section{(5) A summary and clarification of the distinctions drawn}

I have now drawn three distinctions, and will henceforth speak of the following notions of unity: 
(1) B-unity, the unity convertible with Being.

(2) N-unity, the unity which is the principle of Number.

(3) I-unity, the unity explicable in terms of Identity.

If I say that A is B-one I mean that it is a unified whole, as opposed to a divided collection of components. If I say that A is N-one F I mean that it is countable as one $\mathrm{F}$ as opposed to two or more Fs. If I say that A and B are I-one I meand that $A$ and $B$ are the same $F$ as opposed to different Fs.

Further, if I say that A is a B-unit I mean that A possesses the cohesion and structure appropriate to things of its kind. If I say that $A$ is an $\mathrm{N}$-unit I mean tha $A$ is a measure in the counting or measuring of things of its kind. If I say that $A$ is an I-unit I mean that $\mathrm{A}$ is fit to be identified with or distinguished from things.

$\mathrm{N}$-unity can be clarified as follows. An $\mathrm{N}$-unit is what can be counted as one. Hence in Met. I1, 2 Aristotle connects some notion of unity (what I have called $\mathrm{N}$-unity) with measuring, ${ }^{45}$ and uses the notion of indivisibility to explain how it is that something can serve as an N-unit. ${ }^{46}$ From Met. 1052 b32-1053a23 we get the following. At Met. 1053a21-4 Aristotle explicitly draws a distinction between

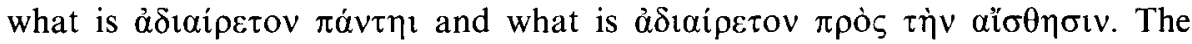
former is said to be the unit or monad, $\tilde{\eta} \mu$ ovás. At Met. 1053a 1-2 the absolutely

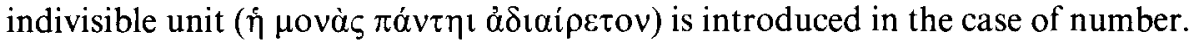
The $\pi \dot{\alpha} \nu \tau \eta \imath \dot{\alpha} \delta$ iai $\rho \varepsilon \tau o v$ unit can helpfully be taken as a unit which cannot in any way be treated as a plurality, which cannot in any way be counted as two or

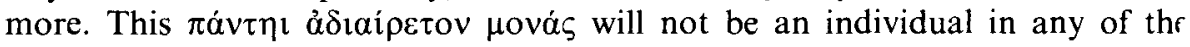
categories, since Aristotle says elsewhere that such $\mu$ ová $\delta \varepsilon \zeta$ are positionless and cannot be in contact but only in succession. ${ }^{47}$ These monads are 'pure numbers', the numbers we count with rather than counted entities. ${ }^{48}$ If we compare

(i) the Pentateuch is five (books)

(ii) the sum of two and three is five

We can see why someone would think of (ii) in terms of pure units which are

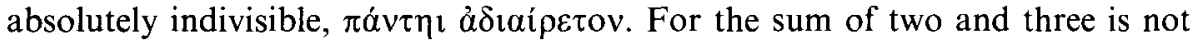
five in some respect; it is not, as a sum of two and three, five of anything. On the other hand the Pentateuch is five just in respect of books, it is five books rather than verses, chapters or pages.

Now we can put pure numbers and pure units to one side, since there are difficulties raised there which are not relevant to my project. For I am concerned with notions of unity insofar as they cast light upon the convertibility of unity and being, and there the concern is with countable things which can come to be, exist and cease to be, rather than with pure units and numbers. ${ }^{49} \mathrm{I}$ am more

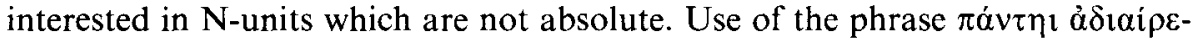
tov suggests that units which are not pure units are those which are not in every way indivisible. That can be understood in terms of completion by a general term F. ${ }^{50} \mathrm{~A}$ unit is non-absolute (or a relative unit) so long as, while it may be divisible simpliciter, it is an $\mathrm{F}$ that is indivisible into $F$ s. The foot, for example, is indivisible 


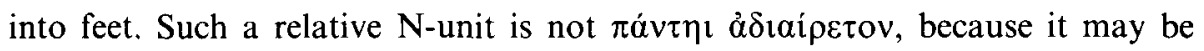
divisible into Gs, as the foot is divisible into inches. This way of putting it connects with Aristotle's relativizing strategy as regards counting, as for example at Met. 1053b24-1054a 12 when Aristotle says that the unit is a definite thing in each class, and a different thing in different classes, a quarter-tone in regard to tunes, a vowel in regard to articulate sounds. ${ }^{51}$

Thus an $\mathrm{N}$-unit is what can serve as a measure, in that it is an $\mathrm{F}$ indivisble into Fs. It can be characterized as N-one F. Man, the foot, the quarter-tone will all be $\mathrm{N}$-units, for each is indivisible in this way. Counting or measuring could not proceed without $\mathrm{N}$-units. We cannot count blue things or mud because in those cases there are no $\mathrm{N}$-units. For we cannot find blue things which are indivisble into blue things, nor mud which is indivisible into mud. It is lack of an $\mathrm{N}$-unit which explains why, as Geach has put it, it is not just the I cannot finish counting the blue things in this room, but I cannot start counting them. For I have no Nunit which I count as one, and use as a measure to count the totality. Hence we see why Aquinas characterizes this notion of unity as the unity which is the principle of number (unum quod est principium numeri). ${ }^{52}$

There is a slight complexity to be noted, for it is not in general true that if an $F$ is an $\mathrm{N}$-unit then all $\mathrm{Fs}$ are indivisible into Fs. Triangles and crowns can be counted, with a triangle and a crown serving as $\mathrm{N}$-units, but triangles can be composed of (and so divisible into) triangles, and the same is true of crowns, as the example of the Papal Crown shows. But the point remains that counting is possible in such cases only because there is an $\mathrm{N}$-unit, which is to say that there are crowns indivisible into crowns (though some crowns may be composed from crowns), and there are actual triangles which are indivisible into actual triangles (though some actual triangles may be composed from actual triangles). ${ }^{53}$

The concept of $\mathrm{N}$-unity and an $\mathrm{N}$-unit should now be reasonably clear. ${ }^{54}$ Then we can see that we do have to distinguish $\mathrm{N}$-unity and I-unity, $\mathrm{N}$-units and Iunits. An I-unit is what can be identifed with and distinguished from things. Thus an I-unit can be picked out as having a history over time, as when we say that there is one $F$ which lasted from $t$ to $t^{*}$ because the $F$ at $t$ and the $F$ at $t^{*}$ are the same F. But an entity can be thus identifiable, even though there could not be counting of such entities, through lack of an N-unit. For example, the same water was in the bath from 6.00 to 7.00 . Hence that water can be taken as an I-unit, since it is one and the same water that remained, though we cannot count under the concept water. If we allow that the items in non-substance categories are nonrepeatable unit properties ${ }^{55}$ then the pink in my face may serve as an I-unit, as when I say that it has remained the same over the past hour, but it is a different and more contentious question whether I can count items of that sort.

That I-units and B-units, I-unity and B-unity are distinct is clear from what I have said earlier, when we saw semi-formal grounds on which to distinguish the use of $\check{v} v$ as an identity predicate from the use of $\tilde{\varepsilon} v$ as a unity predicate. But we 
can see why Aquinas, while emphasizing the importance of the distinction between the unity convertible with being and N-unity, should fail clearly to draw the Bunity/I-unity distinction. For it is arguably the case that whatever is a B-unit is also an I-unit. A B-unit is an item which exhibits the cohesion and structure appropriate to an item of that kind: for example, in the case of a man that would be a certain biological interrelation of limbs and organs, in the case of ice that would be a certain molecular composition and crystalline structure. B-unity conditions are different for different kinds of entity, and since B-unity goes along with being ${ }^{56}$ this will lead to the view that the being of an item is different for different kinds of item.

Thus Aristotle says that, for living things, to be is to be alive. ${ }^{57}$ Similarly, for honey-water to be is for it to be mixed in a certain way, for a book to be is for it to be glued together in a certain way, for a threshold to be is for it to be in a certain position, for ice to be is for it to be solidified in a certain way. ${ }^{58}$ Anything that is, is of a certain kind, ${ }^{59}$ and the unity conditions of that thing are the unity conditions associated with the kind of thing it is. Thus, any B-unit must be characterizable, for some $F$, as $F$, and there must also be the possibility of identifying it and distinguishing it. For if we are to talk of something being, then we have to be able to make sense of its coming-to-be and ceasing-to-be, and that involves the possibility of saying that there is or is not now the same $F$ as there was previously. Hence whatever is a B-unit will also be an I-unit: whatever can be said to have the unity connected with what being is for that kind of thing can also be identified and distinguished ${ }^{60}$ Nevertheless the notion of B-unity is distinct from the notion of I-unity, and we will not understand the rationale of the thesis of the convertibility of unity and being if we think in terms of identity. This is particularly clear once we consider the application of ${ }^{\circ} \mathrm{v} / \varepsilon^{\prime \prime} \mathrm{v}$ in non-substance categories, for the question of what the identity conditions are for non-substance items will not cast light on understanding what the convertibility of unity and being is in those categories.

Given this connection between B-unity and I-unity we would expect I-unity (identity) also to be a transcendental predicate, convertible with being, just as Bunity is. ${ }^{61}$ But B-unity and I-unity are nevertheless distinct. Generally the B-unity of something seems connected with its coming-to-be and passing-away in a way that its I-unity is not. For example, if I wish to bring a ship into existence then it is clarificatory to know that what I need to do is to put the matter appropriate to a ship (for example, wood) into the structure and organization appropriate to ships. Hence there is point in saying that knowing what the B-unity conaitions of a ship are helps me to produce a ship. But this is not so of the I-unity conditions, since it would be unhelpful to be told that to produce a ship I should produce an entity A that stands in the relation 'same ship' to something. It is, of course, no doubt true that if I do produce a ship then I do produce an entity that stands in the relation 'same ship' to something (and vice versa). But even if I understand the 
identity relation 'same ship' this does not help me to produce a ship; and clearly I could produce a ship without understanding the identity relation 'same ship', as indicated by the fact that not every expert shipbuilder can solve the Theseus' Ship problem which is still discussed by philosophers concerned with identity.

The notions of B-unity, I-unity and $\mathrm{N}$-unity are now distinguished and sufficiently clarified. With these distinct notions at hand we have the materials to resolve the textual unclarities noted in Aristotle, since his use of हैv can now be seen as covering these different notions. But I will now turn, rather, to saying what the convertibility of unity and being comes to.

\section{II}

The convertibility of unity and being can now be explicated in terms of the notion of B-unity, rather than I-unity or N-unity. Aquinas' argument at $S T$ la Q.11 Art. 1 clarifies the thesis.

Aquinas argues as follows. To be one means to be undivided: that is, not to be divided or decomposed into component parts. Now, things are either simple or composite. First consider simple things. As simple, each is undivided both actually and potentially, i.e. both undivided and indivisible. Not only is a simple thing not divided into its components, but it could not be, since it has no components into which it could be divided. Hence each simple thing is one (that is B-one) and so for a simple thing to be is for it to be one. Second, consider composite things. A composite thing does not exist if its component parts are separated, but only if they are undivided from one another. Aquinas takes this as plainly so. We can also see it to be true by reflecting that the destruction of something is not a destruction into nothing, but a transformation into relatively disorganized matter - that is, a dividing into material parts. Thus, something's existing is its not being destroyed, which is its not being divided into parts, which is its parts being undivided from one another. Then, to return to Aquinas' text, if the parts of the composite are undivided from one another then the composite is one (as we would say, B-one: that is, an appropriately structured whole). Hence for a composite thing also, for it to be is for it to be one. Then Aquinas' conclusion is that oneness adds nothing real to any existent thing, and that each existing thing is one.

The thought in this passage is not foreign to Aristotle's discussion of unity. We have already noted that "̌v appears as B-unity in some Aristotelian passages. Particularly relevant at this point is a passage not previously cited, de Anima 412b8-9, where in the course of discussing the way in which mind and body are

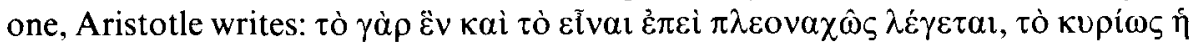

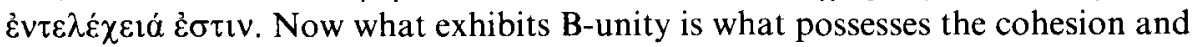
structure appropriate to things of its kind. The parts are in the appropriate structure - undivided in the appropriate way - just when the requisite matter is 
informed in a certain way. Indeed the structure in which they stand to constitute a B-unit just is the appropriate form. It is in virtue of that form that the unstructured parts are an actual, rather than a potential, individual of a certain kind. The form of an F just is the B-unity of an F, the appropriate structuring of parts; and what exhibits that B-unity is an actual F. It is this notion of B-unity which features in Aquinas' argument above. Thus we are justified in connecting Aquinas' argument with one of the notions found in Aristotle's remarks on हैv.

Aquinas' argument seems both successful and clear, and there is little more to say on the convertibility of unity and being in the case of substances directly in relation to the argument. But there are four more general points which need to be made.

(i) It is clear that the notion of being under consideration is what we would call tensed being (tensed existence), rather than the notion of being expressed in the quantifier notation of modern logic. For we are considering the being of an individual entity (for example, this table) as grounded in the unity of this individual entity, and such individual entities have temporal careers, coming into and going out of existence. Hence Aristotle expresses the convertibility of unity and being by saying that they are not separated either in ceasing-to-be or comingto-be ${ }^{62}$ which is to say that for something to come (cease)-to-be is for it to come (cease)-to-be B-one. But the concept of being expressed in the quantifier notation is essentially general, applied to predicates and tenseless. ${ }^{63}$ In this discussion in $S T$ 1a Q.11 Art.1 Aquinas uses the term esse for 'being', which introduces a notion of tensed existence. ${ }^{64}$

(ii) Once clearer on what the notions of being and unity involved in the convertibility thesis are, a certain response to Aristotle's example at Met. $\Gamma 2$ 1003 b26-9 is seen to be inappropriate. Aristotle says that

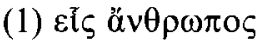

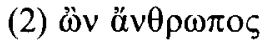
(3) $\alpha \ddot{v} \theta \rho \omega \pi \circ \varsigma$

are the same ( $\tau \alpha$ vó). Now someone could well find it difficult to see a substantial

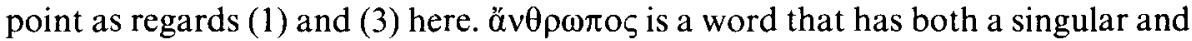
a plural, and so we can tell straight off from the singular form $\alpha \nu \theta \rho \omega \pi$ o

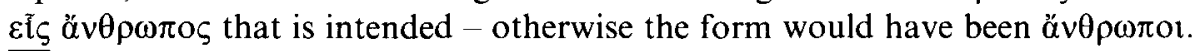
$\overline{\mathrm{Bu}}$ this seems a trivial grammatical point, rather than a substantial metaphysical one. The worry is increased if, switching to English, we take a parallel example with a term without a plural, for example a mass term. 'Mud' and 'one mud' do not seem at all to be the same. 'My bath is full of mud' could well be true, while 'my bath is full of one mud' barely seems sensible. Such examples are often ignored by commentators. For example, Kirwan, commenting on Met. $\Delta 6$ $1015 b 36$ writes: 65 
It is analytic that everything is one something: a plank is one plank, a bundle of planks is one bundle, a consignment of unbundled planks is one consignment.

This use of 'one' as a numerical term does not fit well with such examples as the mud in my bath. The mud in my bath is undoubtedly something, but it doesn't seem analytic that it is one mud in my bath. We could of course introduce a term like 'quantity' ${ }^{66}$ so that it does become true that the mud in my bath is one quantity of mud in my bath, but that seems trivialising if it is done simply to render it analytic that everything is one something. ${ }^{67}$ However, attention to the Bunity/N-unity distinction dissolves the worry about Aristotle's example and shows that worry to be inappropriate, $\varepsilon \tilde{i}_{\zeta}$ is not to be read as ' $\mathrm{N}$-one', so that considerations of singular and plural forms are not to the point. Aristotle's point is rather that 'man' and 'unified man' are the same, for something that is not a unified man, for example a pile of dismembered limbs and organs, just is not a man at all. This point applies just as well in the mud example mentioned above. Were my bath to be full of dissociated mud components (for example, water with soil floating in it) then it would not be full of mud at all.

(iii) Those who have appealed to the unity/being relation to derive atomist conclusions, such as Hume as regards spatial minima, and Leibniz as regards monads, or who have relied on the relation in discussions concerning divisibility, such as Zeno, ${ }^{68}$ have misunderstood the point of the convertibility thesis, taking unity in terms of N-unity. It is for this reason that the reaction to Aristotle's Met. $\Gamma 2,1003 \mathrm{~b} 26-9$ was worth discussing above, for that manifested the same misunderstanding in a far more simple way. Indeed the desire to understand these atomist type arguments is one of the main reasons for wanting to get straight on the convertibility thesis in the first place. A clear reliance on the thesis is found in Leibniz: ${ }^{69}$

To be brief, I hold as axiomatic the identical proposition which varies only in emphasis: that what is not truly one entity is not truly one entity either. It has always been thought that 'one' and 'entity' are interchangeable. Entity is one thing, entities another; but the plural presupposes the singular, and where there is no entity, still less will there be many entities. What clearer statement can be made?

The atomist force of this argument is plain. There is a plurality of things in the world (for example, this table and this chair). The existence of these things is grounded in the existence of the units that compose them, for pluralities exist only insofar as the units composing them exist. It is only units that properly exist, 
since unity and being are the same thing, so that what is not properly one is not properly being either. As Hume says: ${ }^{70}$ "'Tis evident that existence in itself belongs only to unity and is never applicable to number, but on account of the unities, of which the number is compos'd.' Hence there is an argument for the existence of units. In the case of Leibniz these will be monads. It is clear that Leibniz thinks of these unit-monads as the one of a plurality, the units that together make up a many. What characterizes these units, as opposed to the plurality which together they compose, is that each is one as opposed to an aggregated conglomeration. That is, each is an $\mathrm{N}$-unit, an entity countable as just one. Such units provide a measure for the pluralities which they go together to compose. The pluralities are pluralities because they are many of it. We cannot suppose that Leibniz is thinking of unity as B-unity, and the unit in question as a B-unit, for Leibniz takes the unit (the monad) to be simple. ${ }^{71}$ Hence there is no scope for considering the Leibnizian unit in terms of a unified structuring of components - that is, in terms of B-unity - since it has no components.

The Leibnizian type of argument could also be contraposed. If there are grounds for supposing there could be no units for a plurality - as, for example, in Zeno's argument that once something is divided there can never be any end to division $^{72}$ - then since the existence of a plurality would require the existence of units, there could be no plurality. In this sort of argument too unity is taken in terms of N-unity.

Thorough diagnosis of such arguments, and a consideration of what is defensible and what indefensible in them, would require a paper to itself. ${ }^{73}$ It is sufficient to note here that the convertibility thesis relied upon is not that which we have discussed in Aristotle and Aquinas. Indeed, it is not clear how the convertibility thesis as understood by such as Leibniz and Hume - which thesis could be stated as: only what is countable as really one really exists - could possibly have the general application which Aristotle claims for the convertibility of öv and $\check{\varepsilon} v$. For how would the Leibniz/Hume thesis apply to those cases where counting seems inapplicable, as in the mud-example mentioned above, or to the cases of qualities, quantities, relations and so on?

(iv) Even though the convertibility thesis is now clearer in its application in the category of substance, there will still be areas of obscurity. For example, can the various applications of $\ddot{\varepsilon} v$, taken as a notion of B-unity, within the category of substance be matched with what Aristotle says about the various applications of öv? Consider some of the examples Aristotle gives in Met. $\mathrm{H} 2$ while making the point that different things are characterized in different ways. A threshold and a lintel are characterized by position, dinner and breakfast by time, the winds by place. Aristotle concludes that 'it' has different meanings ( $\lambda \dot{\varepsilon} \gamma \varepsilon \tau \alpha \mathrm{t} 1042 \mathrm{~b} 25-6)$ in these different cases. How are we to understand the different applications of $\ddot{\varepsilon} v$ in these cases, and the convertibility of $\ddot{\varepsilon} v$ and öv? A 
threshold exists in that it has a certain position. ${ }^{74}$ If we introduce B-unity by saying that the unity appropriate to a threshold is a structuring of matter in a certain position, then the convertibility thesis seems in danger of becoming trivial. For being in a certain position does not seem part of any concept of unity. Insisting that it does, on the grounds that B-unity and being always go together, seems to make the convertibility thesis trivial, since we rely on the convertibility thesis to clarify what unity is in various, otherwise recalcitrant, cases. The same point could be made about the dinner and breakfast examples.

Now consider the various approaches that could be taken to such cases. First, we might say that the notion of B-unity as explicated has no application to such cases as breakfasts and lintels. But then we abandon the general application of öv/๕̌v convertibility, and given that Aristotle does claim general application for the convertibility thesis it would be a counsel of despair to abandon that, and more likely to be indicative of our not having understood what Aristotle is saying. Second, we might allow that the notion of unity does apply to those cases, and so preserve the general application of the convertibility thesis, but claim that the notion of unity is to be treated differently from the notion of B-unity that we saw in Aquinas' $S T$ 1a Q.11 Art.1 argument. But it was the concepts deployed in Aquinas' argument that provided some insight into the philosophical rationale of öv/̋̈v convertibility. If then we move away from those concepts we begin to lose the benefits of that insight. For example, we might try explicating $\tilde{\varepsilon} v$ in terms of Iunity, saying that the unity of this breakfast which constitutes its tensed existence is a matter of its being identifiable as the same or a different breakfast over time. This would connect time with the being of this breakfast, since time is connected with the identity conditions of breakfasts: my eating cornflakes today and my eating cornflakes yesterday is my eating different breakfasts, because they are eaten at different and discontinuous times. But if we take that line then the difficulties noted earlier about taking I-unity as convertible with and the ground of tensed existence reappear. Further the benefit derived from Aquinas' argument, which does not treat unity as I-unity, is lost. ${ }^{75}$ Third, we might allow that the same notion of B-unity applies in the breakfast case, and then attempt to show how the notion of B-unity has been extended in such a case, for we would no longer be talking in the same way of an appropriate indivision and arrangement of parts. We could of course fairly naturally understand 'indivision and arrangement' themselves in temporal terms. For breakfast is characterized by time in the sense that its parts (for example, the individual chewings, or the individual courses) have an 'internal' temporal arrangement and relation to each other (for example, they are not too widely spaced over time). But Aristotle's point in Met. $\mathrm{H} 2$ is also that breakfast is characterized by the occurrence of the whole (temporally ordered) complex occurring at or over a particular time. The same temporally ordered complex occurring at another time would not be a 
breakfast. Making the natural extension of 'indivision and arrangement' to cover temporal arrangements of parts wil not take in this (external) temporal characterization of breakfast. Fourth, we might say that a breakfast is a cross-categorial complex. ${ }^{76}$ But it is not clear how this move, whatever its independent merits, would avoid unclarity about ôv/घ̌v convertibility. For in Met. H2 Aristotle is precisely considering applications of öv to such cases as breakfast, and what that shows about how ôv is understood, and so we would expect there to be similarly clear applications of $\tilde{\varepsilon} v$, if $\tilde{\varepsilon} v /{ }^{\circ} v$ convertibility is to be preserved in its general application.

These difficulties aside, though, we have got a considerable way with clarifying what $\tilde{\varepsilon} v / o$ o $v$ convertibility involves in the category of substance, and some interesting consequences of the convertibility thesis have emerged. I will, finally, turn to the application of $\tilde{\varepsilon} v / o ̈ v$ convertibility in the non-substance categories.

\section{III}

In the final part of this paper I will say something about how we should understand the convertibility of $\check{\varepsilon} v$ and obv in the non-substance categories. Since I have distinguished B-unity from both I-unity and N-unity we wil not be able to rely on such texts as Met. $\Delta 151021$ a10-14 in order to see what the application of B-unity in the non-substance categories is, since that passage is concerned with Iunity. Further, a necessary preliminary is to say something about what the items in the non-substance categories are. For we need to know what the nonsubstantial items are of which it is held that they are if and only if they are one.

There is a well-known debate as to what non-substantial items are. One alternative is that they are non-repeatable unit properties, for example the brown in this table, or the one foot length in this ruler. These will be spatio-temporally locatable items, specific to the particular substances in which they inhere. They are non-repeatable in that the particular brown in this table canot exist in another table, though there could be in another table another particular brown standing in a similarity relation to the brown in this table, in which case we would say that this table and that table are of the same colour. ${ }^{77}$

The second alternative is that non-substantial items are determinate but repeatable properties, for example the determinate shade of brown (to which we could give a name) which could inhere both in this table and in that. These are non-substantial individuals because they are not said of, or predicated of, anything further. That is, there is nothing such that both the name and the definition of this determinate shade of brown is said of (predicable of) that thing. ${ }^{78}$ For example, the name and the definition are not predicated of this table. 
For suppose that (part of) the definition of this determinate shade of brown is, as we might say, 'a colour reflecting light of wavelength $W$ '. Then it would not be true to say that this table is a colour reflecting light of wavelength $\mathrm{W} .{ }^{79}$

To engage in that controversy over Aristotle's doctrine in the Categories would require a separate paper. Here I have space and time only to say that I will follow the more traditional account whereby non-substantial items are non-repeatable unit properties. ${ }^{80}$ There is a point which does require discussion, however. It might be allowed that Aristotle does introduce non-repeatable unit properties in the early work Categories, but that these do not appear in his later works. ${ }^{81}$ This would be a cause for concern, for the $\tilde{\varepsilon} v /$ ö $v$ convertibility thesis is most clearly stated in the Metaphysics, and not at all in the Categories, so that appealing to the interpretation of non-substance individuals as non-repeatable unit properties in explication of $\tilde{\varepsilon} v / o ̈ v$ convertibility might seem historically inaccurate. However, Heinaman ${ }^{82}$ has cited various passages outside the Categories where Aristotle does assume and mention non-repeatable unit properties. ${ }^{83}$ Further, taking it that non-substance individuals are non-repeatable unit properties allows us to outline a reasonably plausible interpretation of what $\check{\varepsilon} v / o ̈ v$ convertibility in the nonsubstance categories is. It is to that outline that I now turn.

The clearest case is that of qualities. As an example, consider the brown in this desk. What does it mean to say that for it to be and for it to be $\tilde{\varepsilon} v$ are the same thing? As with convertibility in the substance category the concept obv under consideration is that of tensed being. Then the question is: what notion of $\tilde{\varepsilon} v$ is there such that the coming-to-be of the brown in this desk is its attaining B-unity and its ceasing-to-be is its losing that B-unity?

We can start from Aristotle's account of what colours are. Colours are a mixture of white and black, different ratios producing different colours. ${ }^{84}$ It is not necessary to consider what Aristotle's account is of how white and black combine to produce the intermediate colours. ${ }^{85}$ The important point is that the being of, for example, the brown of this desk is constituted by a certain ratio of white and black. The B-unity of this particular brown is then its having the black-white ratio appropriate to it. This seems a reasonable extension of the notion of B-unity explicated by Aquinas in terms of indivision. The relevant indivision in this case is the combination of components (white, black) in a determinate ratio. For black and white to come to be in the appropriate ratio is for the brown in this desk to come to be. The ceasing-to-be of that ratio is the ceasing-to-be of the brown in this desk.

We thus obtain the correct relation between the brown in this desk and the desk in which it inheres. If the desk ceases to be (ceases to be B-one, losing the structuring of components which renders it a desk) then the brown in the desk ceases to be also. Hence, as at Cat. 2b5-6, if the primary substance does not exist 
then the other items do not exist either. Thus we have the primary application of B-unity in the category of substance, as the convertibility with oov should suggest.If the substance ceases to be B-one then the inhering item ceases to be Bone also. Plainly, however, the brown in this desk can cease to be without the desk ceasing to be, as when the desk changes colour. That can be understood as the brown in this desk losing the B-unity, the determinate black-white ratio, which constitutes its being.

Aristotle also gives an account of savours as a combination of sweet and bitter, with different ratios constituting different tastes. ${ }^{86} \mathrm{~A}$ similar account is perhaps possible for odours ${ }^{87}$ and for all the objects of sense. ${ }^{88}$ Then the same account of öv/z̈v convertibility would hold for all the sensible non-substantial items.

I will make only brief remarks about öv/ $/ \tilde{v} v$ convertibility in other nonsubstance categories. The case of quantities appears to be reasonably straightforward. The being of the metre in this ruler is plausibly the arrangement of certain lesser parts in an appropriate order ${ }^{89}$ which is reasonably interpreted as a sort of B-unity. In the case of a relation like being-to-the-left-of an appropriate ordering of the relata would be what constitutes A's being to the left of B..$^{90}$ The case of items in the less commonly mentioned categories such as where, when, having or being-affected ${ }^{91}$ also seems amenable to treatment in terms of the notion of Bunity that I have discussed. Socrates being in the Lyceum is constituted by a certain ordering of Socrates and the Lyceum, Socrates having shoes on by a certain arrangement of Socrates and his shoes.

Again, in the case of the non-substantial categories we see the importance of drawing the B-unity/I-unity $/ \mathrm{N}$-unity distinctions, in order to gain some clarity as regards őv/घ̈v convertibility. For when Aristotle says at Met. 1053b30-1054a13 that in the case of colours the one ( $\tau \dot{0} \ddot{\varepsilon} v$ ) is a colour, for example white, he must be using a notion of $\tilde{\varepsilon} v$ different from that which explicates $\tilde{o} v / \tilde{\varepsilon} v$ convertibility. For any colour will be a unity, in that it is (exists): the notion of है $v$ in that case is B-unity, as explained. But in Met. I2 the point is that white will serve as a unit for the measuring of colours, in much the way that the vowel will serve as a unit for the measuring of articulated sounds: the notion of $\tilde{\varepsilon} v$ there is that of $\mathrm{N}$-unity.

\section{Conclusions}

My aim in this paper has been to generate some puzzlement about, and interest in, the transcendental status of $\tilde{\varepsilon} v$, and the thesis that $\tilde{\varepsilon} v$ and öv are convertible. There are further issues to be discussed about $\tilde{\varepsilon} v / 0 ̈ v$ convertibility, and about the influence of that thesis on later atomist type arguments. Indeed the whole discussion of $\ddot{E} v$ and öv is only part of a much more wide-ranging investigation into all the predicates which were held to be convertible and transcendental both 
in Aristotle and in the Medievals. The questions of what is meant by saying, for example, that good has application in every category ${ }^{92}$ or that good and being are convertible ${ }^{93}$ are both perplexing and fascinating. It is perhaps fortunate that I am not able to go into those issues here. ${ }^{94}$

\section{UNIVERSITY OF SHEFFIELD}

\section{STEPHEN MAKIN}

\section{NOTES}

1. For example, Met. 1003b33; Met. 1054a13-14.

2. For example, Met. 1003b23-31; Met. 1054a15-16; Met. 1061a15-18.

3. The Scholastics later took being, unity, good, something, true as convertible predicates. On being and unity see Aquinas ST 1a Q.11 Art.1; on being and good see Aquinas ST Q.6 Arts. I,3. Since being is transcendental then any predicates convertible with being will also be transcendental. Aristotle affirms the transcendental status of good at NE 1096a23-7, EE 1217b26-32 (though the consequence drawn in $E E$ concerning the possibility of a single science of being is different from that drawn in Met. $\Gamma 2)$. On the relation of unity and being in Plato, see Parm. 142e, 144e. See also Ross' helpful note in Aristotle's Metaphysics I (1924) 256.

4. See for example Leibniz' letter to Arnauld, 30 April 1687, The Leibniz-Arnauld Correspondence (translated H. T. Mason) (1967) 121; Hume, Treatise on Human Nature 1.2.2; on Zeno, Philoponus in Phys. 42.9-43.6, 80.23-81.7, Simplicius in Phys. 99.12-16. Compare also Aquinas' remarks on the use of this relation by Plato and the Pythagoreans, ST 1a Q.11 Art.1 ad 1, Comm. in Met. prs. 900-1, and by Avicenna, Comm. in Met. prs. 556-60, 1981-2. Aquinas' Commentary on Aristotle's Metaphysics is translated by J. P. Rowan, Aquinas' Commentary on the Metaphysics of Aristotle, 2 vols. (1961).

5. See the passages mentioned in Part 1 below.

6. See for example Annas, 'Individuals in Aristotle's categories: two queries', Phronesis 19 (1974) 146-52; Kirwan, Aristotle's Metaphysics Books $\Gamma \Delta E$ (1971) 134; Annas, Aristotle's Metaphysics, Books $M$ and N (1976) 38.

7. See for example White, 'Aristotle on sameness and oneness', Philosophical Review 80 (1971) 177 97; Fred Miller disagrees with White's conclusions in his 'Did Aristotle have the concept of identity?', Philosophical Review 82 (1973) 483-90. White in his paper notes that Aristotle did not keep separate two uses of ' $X$ and $Y$ are one', first to mean that $X$ is somehow identical with $Y$, second to mean that $\mathrm{X}$ and $\mathrm{Y}$ make up one thing. As a result Aristotle does not separate a one and a two place usage of 'one'. For more on White's point see the text in Part 1 below.

8. Perhaps as Annas, Aristotle's Metaphysics $M$ and $N 38$, 'Aristotle is the victim here of the Greek language' so that it is unreasonable to expect him to draw the relevant distinctions. See also Schofield 'Plato on unity and sameness', CQ n.s. 24 (1974) 33-45, with an account offered of why Aristotle should have conflated ह̌v and $\tau \alpha u ̛ v o$, especially in face of Plato's argument for their distinction at Parm. 139d, e.

9. On these issues see the collection of papers Rorty, Schneewind and Skinner (eds.), Philosophy in history (1984), particularly the paper by Rorty, 'The historiography of philosophy: four genres', 49 
75. See also David Charies' discussion of the distinction between philosophical scholarship, traditional classical scholarship and original speculation inspired by the reading of a text in his Aristotle's Philosophy of action (1984) ix-xi. For consideration of these issues in the special case of exegesis in the face of limited textual evidence see my 'How can we find out what ancient philosophers said?', Phronesis 33 (1988) 121-32.

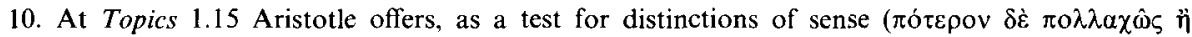
$\mu o v \alpha \chi \hat{\omega} \zeta \tau \hat{\omega} \iota \varepsilon \iota \delta \varepsilon \iota \lambda \dot{\varepsilon} \gamma \varepsilon \tau \alpha \iota 106 \mathrm{a} 9$ ) within a term, distinctions in its contraries.

11. I intend only to show that 'one' is treated differently in each of the questions, and to show this by the difference between the types of answers which are appropriate. I do not intend the answers offered to be either Aristotelian answers or correct answers.

12. This point is worth making over and above the first point, for it shows that not all uses of 'one' as a unity predicate are one place usages. Thus it does not follow from a particular use of 'one' as a two place predicate that the term is there used as an identity predicate.

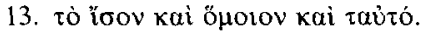

14. Met. $1003 \mathrm{~b} 22-1004 \mathrm{a} 10$.

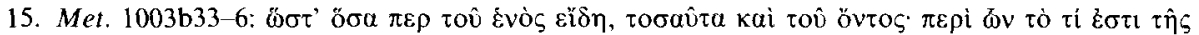

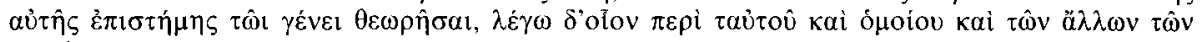

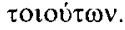

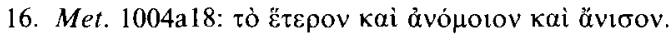

17. Met. $1018 \mathrm{a} 45$.

18. Met. $1018 \mathrm{a} 7-9$.

19. Met. $1004 \mathrm{~b} 27$.

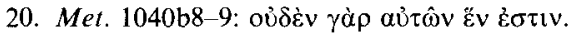

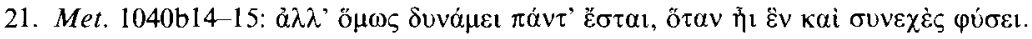

22. Phys. 227a10-34.

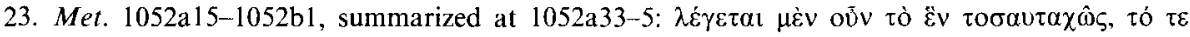

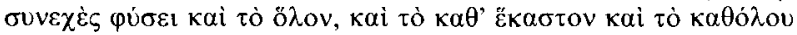

24. On focal meaning see G. E. L. Owen, 'Logic and metaphysics in some earlier works of Aristotle' in Owen's collected papers: M. Nussbaum (ed.), Logic, Science and Dialectic (1986) 180-99.

25. Met. 1003b5-10, 1060b31-1061a10.

26. Clearly the example offered here requires for its relevance that the items in non-substance categories are taken in a certain way, i.e. as non-repeatable unit properties, for example the particular white in Socrates, or the particular five foot in Callias. I will say more about this interpretation in Part III below. 


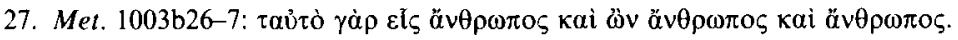

28. Met. 1054a29-32.

29. I give the text as printed by Ross, rather than that given by Jaeger, in the Oxford Classical Texts

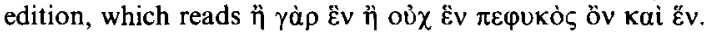

30. As Plato saw, Parm. 128e-129d, applied to like and unlike, many and one.

31. Met. 1052a15-1052bl, cited earlier.

32. See Met. $1045 \mathrm{a} 8-12$.

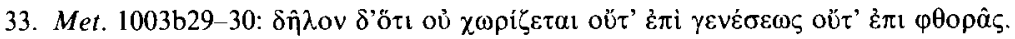

34. I take this to be similar to Geach's claim that count nouns (for example 'man') are derelativisations of equivalence relations (identity relations, for example "- is the same man as -'). See Geach, Reference and generality (1968) para. 109, and 'Ontological relativity and relative identity' in M. K. Munitz (ed.), Logic and ontology (1973) 287-302, especially 290-2.

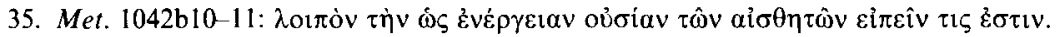

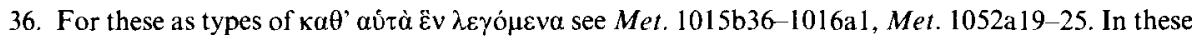
passages $\tilde{\varepsilon} v$ is treated as a unity predicate.

37. Wright, Wittgenstein on the foundations of mathematics (1980) viii.

38. See ST 1a Q.11 Art.1 ad 1, Q.11 Art.2; also Comm. in Met. prs. 501, 557, 559, 560, 875, 901, 1981, 1997, 2090. Aquinas makes the distinction also in his early Commentary on the de Trinitate of Boethius (the first four questions of which are translated as Faith, reason and theology by A. Maurer (1987)). See Q.4 Art.1, especially Objection 3.

39. ST 1a Q.11 Art.1 ad 1; Comm. in Met. prs. 501, 556-60, 900-1, 1981.

40. On Aquinas' Commentaries on Aristotle see Joseph Owens, 'Aquinas as an Aristotelian commentator' in J. R. Caton (ed.), St Thomas Aquinas on the existence of God: the collected papers of Joseph Owens (1980) l-19.

41. There is a notion of division connected with, or implied by, the e̊v convertible with being, since that concept of $\tilde{\varepsilon} v$ is a concept of indivision, as at $S T$ la Q.11 Art.1, unum enim nihil aliud significat quam ens indivisum. Compare also Comm. in Met. pr.501.

42. Comm. in Met. pr.2090 is a little complicated, since Aquinas says there that the notion of plurality opposed to the $\ddot{E} v$ convertible with being (viz. plurality taken absolutely) is in a sense the genus of number. He makes a similar claim at pr.2091. On the other hand, $\tilde{\varepsilon} v$ taken as a measure is limited to the category of quantity. At this point the distinction between the $\tilde{\varepsilon} v$ convertible with being and the $\tilde{\varepsilon} v$ which is the principle of number may seem to become cloudy.

43. See Met. $1052 b 18-19$. 
44. The interesting example of the Papal Crown is taken from David Wiggins' Sameness and substance (1980) 73. However, Wiggins makes a different use of the example, saying that there is 'no definite answer' to the question of how many crowns the Pope has on his head.

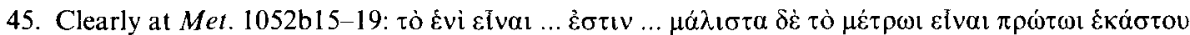

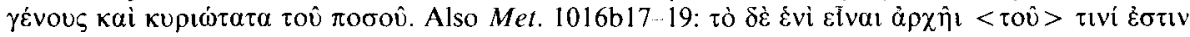

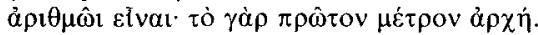

46. Aristotle does not, of course, use the term ' $\mathrm{N}$-unit' nor does he explicitly draw the distinctions I have drawn between $\mathrm{N}$-units, B-units and I-units: this is part of the source of the problem I am interested in. What I mean is that the notion Aristotle is talking about is identifiable as what I have called $\mathrm{N}$-unity. I will not make this disclaimer again.

47. See Post. An. 87a36, 88a33; Phys. 227a30; de Caelo 300a18; Met. 1069a12, 1084b26. Since individuals do have a position, and (at least in some categories) can be in contact, these monads cannot be individuals from one of the categories.

48. On this distinction see Phys. 219b5-9.

49. Annas, Aristotle's Metaphysics $M$ and $N$ especially 26.41 is clear and concise on Aristotle's ideas concerning numbers.

50. I do not intend that $\mathrm{F}$ should be limited to sortal terms. The foot is an $\mathrm{N}$-unit, but 'foot' is not a sortal term.

51. Compare also Phys. 223b14-15, 224a3-15, Met. 1016b20-4, 1053a24-7, 1087b33-1088a 14. In citing these passages, and in explicating what Aristotle says by means of the completion of number terms by general terms, I do not mean to suggest that Aristotle wholly prefigures Frege's insight that numbers are properties of concepts. Indeed I do not mean to offer any general view on Aristotle's account of numbers and counting. Rather, the completion of number terms by general terms in explication of indivisibility and $\mathrm{N}$-unity (and later as regards B-unity too) is useful for putting matters clearly; it also answers to ideas that are found in Aristotle.

52. See references at $\mathrm{n} .38$ above.

53. I say 'actual triangles' because the kind of example $I$ have in mind is this. The actual triangle $\mathrm{ABC}$ is composed of (and so divisible into) the actual triangles ADE, DBF, DEF, EFC. But the totality is countable (as five triangles) because there is an $\mathrm{N}$-unit, e.g. the actual triangle ADE is indivisible into any further actual triangles. Clearly, however, $\mathrm{ABC}$ (or any triangle) can be divided into any number of potential triangles. Thus the order 'count the potential triangles in $\mathrm{ABC}$ ' could not be followed, precisely because there is no $\mathrm{N}$-unit in that case.

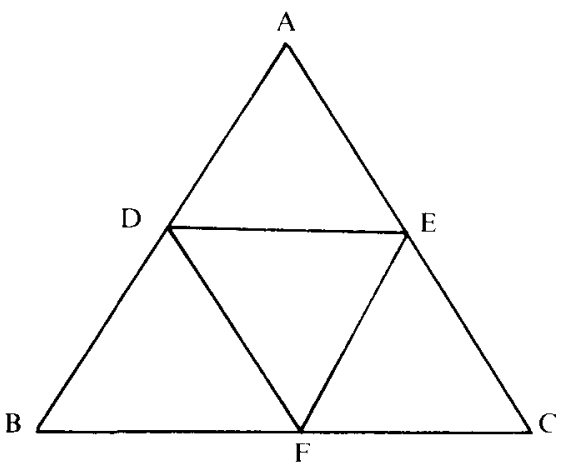

54. As an aside we can see why Aristotle claims, as at Met. 1052b18-20, that the primary application of this concept is in the category of quantity. If we consider the categories as dividing up different questions that might be asked about things, as Ackrill mentions in his Aristotle's Categories and de 
Interpretatione (1963) 78-9, and on which compare Topics 1.9 , then the question 'how many?' will receive an answer in the category of quantity. Counting that team as 11 (men) does not say what it is (substance) or what it is like (quality) or..., but how many it is (quantity). Note that in Cat. 6 number is repeatedly given as an example of quantity, 4b22, $4 \mathrm{~b} 25,5 \mathrm{a} 23,5 \mathrm{a} 30,6 \mathrm{a} 20$

55. I shall say more about this in Part III below.

56. I shall say something more about this convertibility presently, though it should now be becoming fairly clear what convertibility involves.

57. de Anima 415b13. Also GC 318b25; NE 1166a4. It is on the same grounds that Aristotle denies that a dead man is a man, de Int. 21a21-2.

58. For these examples see Met. 1042b15-1043a11.

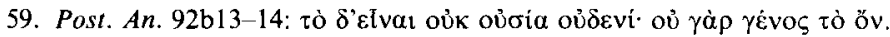

60. Hence Quine's well-known slogan 'no entity without identity'.

61. As Geach conjectures, 'Ontological relativity and relative identity' (n.34) 287-8. But that I-unity might also be convertible with being should give us no more reason to deny the distinction between Iunity and B-unity than does the convertibility of being and good give us reason to deny the distinction

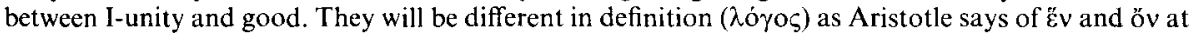
Met. 1003b24-5.

62. Met. $1003 \mathrm{~b} 29-30$.

63. On the irreducibly general nature of the quantifier notation concept see Barry Miller, 'In defence of the predicate "Exists" , Mind 84 (1975) 338-54 on the distinction between precisely one individual and one precise individual.

64. On Aquinas' use of esse see Anscombe and Geach, Three philosophers (1961) 88-100 (by Geach), especially his comment at 91: 'It is the present-actuality sense of 'est' that is involved in Aquinas' discussions of ens and esse. It corresponds to the uses of the verb 'to exist' in which we say that a thing comes to exist, continues to exist, ceases to exist....' Owen in his discussion of Aristotle at 'A ristotle on the snares of ontology' in Bambrough (ed.), New essays on Plato and Aristotle (1965) 69-95 expresses the tensed/tenseless distinction as between being* and being** respectively.

65. Kirwan (n.6) 135.

66. As introduced by Helen Cartwright. See her 'Heraclitus and the bath water', Philosophical Review 74 (1970) 466-85; 'Quantities', Philosophical Review 79 (1970) 25-40; 'Amounts and measures of amount', Nous 9 (1975). I do not suggest that Cartwright introduces the notion of a quantity in a trivialising way, so as to render it analytic that everything is one something: she has her eye on certain important problems about material identities.

67. We can give another example, not using a mass term, by picking an English term whose singular and plural forms are the same. 'Sheep' and 'one sheep' do not seem the same: compare 'I own sheep' and 'I own one sheep'.

68. See the passages cited at n.4 above. 
69. Translated by H. T. Mason, reference at n.4 above.

70. Reference at n.4 above.

71. Leibniz, Monadology pr.1.

72. Zeno Bl. On the interpretation of this argument, and its lack of reliance on the claim that every magnitude is divisible (as distinct from the claim that once a magnitude is allowed to be at all divisible then it is infinitely divisible) see my 'The indivisibility of the atom', Archiv für Geschichte der Philosophie (forthcoming).

73. I undertake such a diagnosis in an unpublished paper 'Unity'.

74. Met. 1046b26-7.

75. White (n.7 above), especially 191-5, explains Aristotle's conflation of ' $X$ is identical with $Y$ ' and ' $\mathrm{X}$ and $\mathrm{Y}$ go together to make up a single thing' in terms of Aristotle's concentration on problems concerning identity over time. For the question 'what makes Socrates yesterday identical with Socrates today?' might also be put as 'what makes Socrates yesterday and Socrates today go to make up a single thing (viz. Socrates)?' Now White does not draw precisely the distinctions I have drawn, but, insofar as he emphasizes temporal considerations and the unity of motion, we might take his approach as leading to the view canvassed above, that the unity convertible with being is to be understood in terms of identity.

76. Ackrill, 'Aristotle on 'Good" and the Categories' in Barnes, Schofield and Sorabji (eds.), Articles on Aristotle II (1977) 17-24, makes a similar point when considering the transcendental status of good, concerning examples such as white man and negro (a substance and a quality) and doctor (a substance and an action). See also Kosman, 'Animals and other beings in Aristotle', in Gotthelf and Lennox (eds), Philosophical issues in Aristotle's biology (1987) 360-91, especially 367-71.

77. For this interpretation see Ackrill (n.54) 74-75, and Anscombe (n.64) $7 \cdot 19$.

78. Cat. 2a19-33.

79. For this interpretation see Owen, 'Inherence', Phronesis 10 (1965) 97-105. See also M. Frede, 'Individuals in Aristotle' in his Essays in ancient philosophy (1987) 49-71.

80. For a defence of the traditional interpretation against Owen I have found particularly useful and convincing Heinaman's paper 'Non-substantial individuals in the Categories', Phronesis 26 (1981) 295-307. Other papers relevant to this controversy are Allen, 'Individual properties in Aristotle's Categories', Phronesis 14 (1967) 31-9; Duerlinger, 'Predication and inherence in Aristotle's Categories', Phronesis 15 (1970) 179-203; Jones, 'Individuals in Aristotle's Categories', Phronesis 17 (1972) 107-23; Annas 'Individuals in Aristotle's Categories: two queries', Phronesis 19 (1974) 146-52; Jones, 'An introduction to the first five chapters of Aristotle's Categories', Phronesis 20 (1975) 146-72. Hartman, Substance, body and soul (1977) also makes relevant points, endorsing the traditional view at, for example, 14 n.5.

81. See, for example, Jones, Phronesis 17 (1972) 107. Annas, Aristotle's Metaphvsics $M$ and N, 204 makes the distinct, and acceptable, point that only at Met. 1089b24-8 does Aristotle explicitly consider the question of non-substantial individuals, outside Categories. But what she says there is compatible with both the traditional interpretation and Owen's interpretation. 
82. Heinaman (n.80) 297-99. See also Engmann, 'Aristotelian universals', CP 17 (1978) 17-23.

83. The most interesting are Phys. 228a3-12 (a particular person's health, a particular man's walking); Phys. 242a66-242b4 I (a motion is numerically one if it proceeds from something that is numerically one to something that is numerically one, for example, from a particular white to a

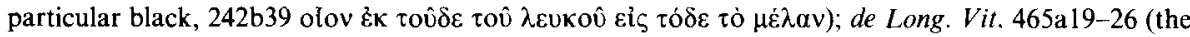
termination of what must be a particular ignorance or a particular knowledge); Met. 1040b25 (what is one cannot be in many things at the same time, so one brown will have to be a non-repeatable unit property, this brown); Met. 1044b21-9 (the coming-to-be of what must be a particular white); Met. 1070a21-4 (the existence of the shape of a (particular) bronze sphere). Heinaman also cites other passages, but requires some discussion to reveal in them Aristotle's endorsement of non-repeatable unit properties. For these the reader is referred to Heinaman's paper.

84. de Sensu 440b18-23, 442a12; also Cat. 12a17-19; Phys. 188b3-5; Met. 1070b19-20, which gives white as the form, black as the privation and the surface as the matter.

85. At de Sensu $439 \mathrm{~b} 20-440 \mathrm{~b} 25$ Aristotle considers and rejects a juxtaposition account, where white and black are juxtaposed, each separate white and black being invisible, but producing a visible intermediate colour, and a superposition account, whereby one is seen through the other, various ratios of superposition producing intermediate colours. Aristotle prefers an account based on complete mixture, $440 \mathrm{~b} 14-17$.

86. de Sensu 442a13-18.

87. de Sensu 442b29-30, though this is unclear.

88. de Sensu 445b25-8. Every object of sense has contrariety, as white and black in the case of colour, sweet and bitter in the case of taste. On sounds see also de Sensu 448a2-14.

89. See Cat. 6 on the explication of quantities in terms of parts, whether related to one another (as the parts of a line) or not (as the parts of a number).

90. The case of such relatives as great, small, half, double will be a more difficult one. For, as noted by Annas, Aristotle's Metaphysics $M$ and $N$ (n.6) 198, it appears to be of such relatives as these that

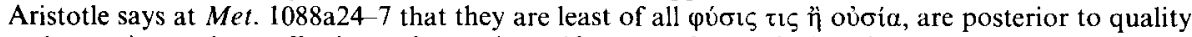

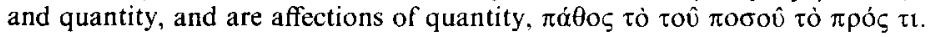

91. The list of ten categories at Cat. $1 \mathrm{~b} 25-2 \mathrm{a} 3$ is repeated only at Topics $103 \mathrm{~b} 20-2$. I have nothing to say here on whether Aristotle held there to be ten categories throughout his writings.

92. Se for example $N E 1096 \mathrm{a} 23-7, E E$ 1217b26-32.

93. Argued by Aquinas at $S T$ la Q.6 Art.1.

94. I would like to thank Robert Wardy and the Editors for their helpful comments on earlier forms of this paper. 